\title{
Comparative study of fasting lipid profile among non-smokers and smokers \\ Arulmurugan $\mathrm{C}^{1, *}$ and Adarsh Yatheesh ${ }^{1}$ \\ ${ }^{1}$ Department of Medicine, Vinayaka Mission's Kirupananda Variyar Medical College and Hospitals, Chinna Seeragapadi, \\ Salem, Tamilnadu-636308, India
}

\begin{abstract}
Background: Inadequate evidence is found about dyslipidaemia from smoking in India. The jeopardy of dissimilar medical complications is regularly reflected as augmented in the circumstance of cig burning. The pervasiveness amongst countryside and town Indians of beedis and tobacco often gives rise to the occurrence of coronary artery illnesses.
\end{abstract}

Aim: the study aims to assess the variation of lipid profile and dose-related vicissitudes among the non-smokers and smokers by assessing the number of daily amount of beedis and cigarette's.

Materials and methods: We performed a cross sectional investigation for a period of one year in our hospital. The participants of this study were mostly of age 15-55 years and their BMI is below 25 .

Results: All the lipid variables except HDL-C were found high among smokers when compared to the nonsmokers, while in the smoker group the HDL-C levels were lower than non-smokers and statistically important differences were observed.

Conclusion: The study concluded that there is a variation in lipid variables in the smokers serum such as VLDL, TGs, TC and LDL were elevated and that of reduction in HDL is found. This variability causes adverse cardiovascular events and cerebrovascular disease. Lipid profile should be evaluated in smokers to mitigate the risk of coronary artery and the related disease. They will be briefed on the health risks of smoking. They should be convinced to leave cigarette consumption to healthier lifecycle and embrace better lives.

Keywords: lipid parameters; non-smokers; smokers

*Corresponding author: Dr. Arulmurugan C. MD., Associate Professor, Department of Medicine, Vinayaka Mission's Kirupananda Variyar Medical College and Hospitals, Chinna Seeragapadi, Salem, Tamilnadu-636308, India. Mobile: +91 9710919719; Email: dr.arulc@gmail.com

Received 30 March 2019; Revised 25 May 2020; Accepted 5 June 2020; Published 16 June 2020

Citation: Arulmurugan C, Yatheesh A. Comparative study of fasting lipid profile among non-smokers and smokers. J Med
Sci Res. 2020; 8(3):94-99. DOI: http://dx.doi.org/10.17727/ JMSR.2020/8-13

Copyright: (C) 2020 Arulmurugan C et al. Published by KIMS Foundation and Research Center. This is an open-access article distributed under the terms of the Creative Commons Attribution License, which permits unrestricted use, distribution, and reproduction in any medium, provided the original author and source are credited. 


\section{Introduction}

Cigarette smokers are usually observed as connected with a rising possibility of a diversity of medicinal circumstances [1]. Frequent technical lessons have recognized cigarette smokers as single foremost cause for avoidable illness and death besides as a worldwide frontrunner in illness inescapability [2]. Disease must also be diminished. Nicotine after tobacco burn and additional toxic complexes was inspired and circulated in the human body especially with lungs. The poisonous compounds and nicotine are found to be absorbed with the help of lungs which in turn disturbs it throughout the body with the help of circulation. The body of smokers consists of a huge amount of nicotine that develops plagues at a slower rate compared to the body of the non-smoker. The bad fats (TC), triglycerides (TG), LDL-C were raised in the body due to nicotine and that of good fat that is HDL-C is found to be reduced [3]. These variations develop ischemic cigarette smoking and coronary heart illness and there is no such numerical material is presently presented on Sudanese ingesting of tobacco. Not any investigation additional proposes the connotation of tobacco by way of the bulk of burned roll-ups a diurnal, smoking extent and the consequence on the serum fat summary $[4,5]$.

Presently there is an ample of argument done regarding lipid outline constituents are frequently changed in retort to roll-ups; profile constituents straight or circuitously disturb further constituents, and vice-versa.

In terms of production of tobacco and its exportation, India is the foremost country. Loads of tobacco is manufactured yearly. About partial of the drug is free for indigenous people [6]. There are several forms by which tobacco can be consumed such as smoking; chewing and different forms of cigarettes are beedi, hukka, cigarette and pipe. Burning is completed otherwise. Cigarette and Beedi smoking are common in urban and rural India [7, 8]. In India, the level smoking dyslipidaemia is not appropriately recognized. By means of tobacco is still mutual. Augmented pervasiveness of coronary artery illness amongst countryside and city Indians. Consequently, the current learning explores how chronic smokers and non-smokers regulate their serum lipid summary and uncertainty there is dose-related changes in serum lipid summary amongst chronic -smokers.

\section{Methodology}

Study design: Cross-sectional study

Study subjects: Smokers and non-smokers

\section{Inclusion criteria:}

- $\quad$ Cases- It included 100 healthy male smokers in age group of 15-55 years, who have smoked more for 5 years or more. Controls- It included 100 age matched healthy men who have never smoked.

- $\quad$ Patients in the age of 15 to 55 years

- $\quad$ Subjects with Body Mass Index (BMI) are less than 25.

- Subjects on normal balanced Indian diet

\section{Exclusion criteria:}

- Both for smokers and non smokers:

- Patients with diabetes, nephrotic syndrome, alcoholism, hypertension, patient on any anti hyperlipedemic drugs (HMG co ASE inhibitors, fibric acid derivatives, niacin), patients on beta blockers, diuretics and patient on diet restriction were excluded from the study

- Sample size:

- 200 subjects. 100 smokers and 100 nonsmokers.

\section{Study procedure}

The study was started after getting the approval from the institutional ethical committee. Informed consent was obtained from all the subjects participating in the study. A semi-structured questionnaire was designed to collect the data regarding the diet and smoking habits from the study subjects. $3 \mathrm{ml}$ of venous blood was collected in plain vial after 12 hours overnight fasting. Serum was separated by centrifugation and used for the estimation of serum lipid profile estimation.Lipids were analysed by methods of cholesterol oxidase para aminoantipyrine, Lipase/glycerol kinase (LIP/ GK), enzymatic reaction respectively LDL-C, VLDL-C were measured by Friedewald formula.

\section{Results:}

Majority of the study subjects both in the smoker and non-smoker group were between 30 to 40 years of age with a average mean age of 36.6 years among smokers and 37.4 years among non-smokers and 
no statistical significant difference was observed between the two groups.It is seen from the study subjects that majority of the smokers gave the history of smoking between 5 and 10 years with a mean years of smoking as 13.3 years. It is seen from the study that majority of the smokers gave the history of smoking $10-15$ cigarette/bee dies per day with a mean of 16.8 cigarettes or beedis per day It is depicted from the study that the mean pack years among the smokers was 10 pack years with a minimum of 5 and a maximum of 27 years.

Table 1: Comparison of triglycerides between smokers and non-smokers.

\begin{tabular}{|cccc|}
\hline Triglycerides & $\begin{array}{c}\text { Smokers } \\
(n=100)\end{array}$ & $\begin{array}{c}\text { Non-smokers } \\
(n=100)\end{array}$ & P value \\
\hline$<100$ & 10 & 18 & \\
$100-150$ & 30 & 50 & \\
$150-200$ & 32 & 28 & $<0.001$ \\
$201-250$ & 20 & 4 & \\
$>250$ & 8 & 0 & \\
Mean \pm SD & $169.4 \pm 32.4$ & $130 \pm 30.5$ & \\
\hline
\end{tabular}

$\mathrm{p}$ value derived by applying student $\mathrm{T}$ test.

The mean triglycerides level among the smokers was $169.4 \mathrm{mg} / \mathrm{dl}$ and among the non-smokers it was $130 \mathrm{mg} / \mathrm{dl}$ and it was statistically significant $(\mathrm{p}<0.0001)$.

Table 2: Comparison of total cholesterol between smokers and non-smokers.

\begin{tabular}{|lccc|}
\hline Total cholesterol & $\begin{array}{c}\text { Smokers } \\
(n=100)\end{array}$ & $\begin{array}{c}\text { Non-smokers } \\
(n=100)\end{array}$ & P value \\
\hline $100-150$ & 10 & 18 & \\
$150-200$ & 30 & 50 & \\
$201-250$ & 32 & 28 & $<0.001$ \\
$>250$ & 20 & 4 & \\
Mean \pm SD & $200.4 \pm$ & $169 \pm 29.4$ & \\
\hline
\end{tabular}

$\mathrm{p}$ value derived by applying student $\mathrm{T}$ test.

The mean total cholesterol level among the smokers was $200.4 \mathrm{mg} / \mathrm{dl}$ and among the non-smokers it was $169 \mathrm{mg} / \mathrm{dl}$ and the difference between the two groups was found to be statistical significant $(\mathrm{p}<0.0001)$.
Table 3: Comparison of HDL cholesterol between smokers and non-smokers.

\begin{tabular}{|cccc|}
\hline HDL cholesterol & $\begin{array}{c}\text { Smokers } \\
(n=100)\end{array}$ & $\begin{array}{c}\text { Non-smokers } \\
(n=100)\end{array}$ & P value \\
\hline$<20$ & 10 & 18 & \\
$20-30$ & 30 & 50 & \\
$31-40$ & 32 & 28 & $<0.001$ \\
$41-50$ & 20 & 4 & \\
Mean \pm SD & $34.7 \pm 6.1$ & $41.2 \pm 3.2$ & \\
\hline
\end{tabular}

$\mathrm{p}$ value derived by applying student $\mathrm{T}$ test.

The mean HDL cholesterol level among the smokers was $34.7 \mathrm{mg} / \mathrm{dl}$ and among the non-smokers it was $41.2 \mathrm{mg} / \mathrm{dl}$ and the difference between the two groups was found to be statistical significant $(\mathrm{p}<0.0001)$.

Table 4: Comparison of LDL cholesterol between smokers and non-smokers.

\begin{tabular}{|cccc|}
\hline LDL cholesterol & $\begin{array}{c}\text { Smokers } \\
(n=100)\end{array}$ & $\begin{array}{c}\text { Non-smokers } \\
(n=100)\end{array}$ & P value \\
\hline$<100$ & 18 & 52 & \\
$100-150$ & 49 & 42 & \\
$151-200$ & 31 & 6 & $<0.001$ \\
$201-250$ & 2 & 0 & \\
Mean \pm SD & $133 \pm 34.3$ & $104.3 \pm 26.7$ & \\
\hline
\end{tabular}

$p$ value derived by applying student ' $t$ ' test.

The mean LDL cholesterol level among the smokers was $133 \mathrm{mg} / \mathrm{dl}$ and among the non-smokers it was $104.3 \mathrm{mg} / \mathrm{dl}$ and the difference between the two groups was found to be statistical significant $(\mathrm{p}<0.0001)$.

Table 5: Comparison of VLDL cholesterol between smokers and non-smokers.

\begin{tabular}{|cccc|}
\hline VLDL cholesterol & $\begin{array}{c}\text { Smokers } \\
(n=100)\end{array}$ & $\begin{array}{c}\text { Non-smokers } \\
(n=100)\end{array}$ & P value \\
\hline$<20$ & 10 & 18 & \\
$20-30$ & 34 & 50 & \\
$31-40$ & 36 & 30 & $<0.001$ \\
$41-50$ & 12 & 2 & \\
$>50$ & 8 & 0 & \\
Mean \pm SD & $32.7 \pm 10.1$ & $25.9 \pm 6.9$ & \\
\hline
\end{tabular}

$\mathrm{p}$ value derived by applying student ' $\mathrm{t}$ ' test. 
The mean VLDL cholesterol level among the smokers was $32.7 \mathrm{mg} / \mathrm{dl}$ and among the non-smokers it was $25.9 \mathrm{mg} / \mathrm{dl}$ and the difference between the two groups was found to be statistical significant $(\mathrm{p}<0.0001)$.

It is seen from our study that the all the lipid parameters except HDL -C shows significant direct correlation with number of pack years, as the number of pack years increases the triglycerides level, total cholesterol levels, LDL, VLDL increases and it is found to be statistically significant, whereas a strong negative correlation was seen between the HDL levels and pack years.

Table 6: Correlation between various lipid parameters with the number of cigarette smoked /day.

\begin{tabular}{|c|c|c|c|c|c|}
\hline \multirow{2}{*}{ No.of cigarette/day } & \multicolumn{5}{|c|}{ Lipid parameter } \\
\hline & Triglycerides & Total cholesterol & $H D L$ & $L D L$ & $V L D L$ \\
\hline Mild smokers $(1-10$ cigarette) (pack years $<10$ ) & 161.5 & 189.8 & 36.8 & 128.7 & 30.8 \\
\hline $\begin{array}{l}\text { Moderate smokers (11-20 cigarette) (pack years } 10 \\
-20 \text { ) }\end{array}$ & 173.8 & 205.6 & 33.4 & 134.9 & 32.9 \\
\hline Severe smokers $(>20$ cigarette) (pack years $>20$ ) & 177.5 & 217.8 & 28.6 & 138.7 & 35.7 \\
\hline r value & 0.891 & 0.813 & 0.788 & 0.812 & 0.815 \\
\hline $\mathrm{p}$ value & $<0.0001$ & $<0.0001$ & $<0.001$ & $<0.001$ & $<0.001$ \\
\hline
\end{tabular}

\section{Discussion}

Smoking is the chief jeopardy influence in established states. The study included 100 people in both non-smokers and smokers group for analysis of lipid profile. Vicissitudes in smokers to LDL, TC and VLDL over non-smokers have developed statistically noteworthy. Impartial cigarette burn, the danger of demise from coronary artery illness, documented approximately $70 \%$ rise. Adedeji et al. investigated the considerable increase in LDL serum cholesterol $(p<0.05)$ comparative to non-smoker [9]. On the other hand, there is no such significant variation is found in the level of VLDL and triglycerides between the two groups that is non-smokers and smokers $(\mathrm{p}<0.01)$. The level of HDL is found to be higher among non-smoker group than smokers groups. In an extra investigation by Makoto et al., the mean alteration amid non-smokers and smokers was solitary statistically noteworthy $(\mathrm{p}<0.05)$. Both the groups were matched to identify the variation level of LDL, TC and VLDL at $p<0.05$. The value of mean HDL's was found to be reverse in this case that is it is elevated among the non-smoker group at $(p<0.05)$ [10].

The study showed similar result by both Neki et al. and Jaleel et al. $[11,12]$. The serum level of TC is tailed with both the non-smoker and smoker group. Same observation is found among other components such as LDL, TG, VLDL and HDL intended for non- smoker [13]. A report in the 2013, by Rao and Subash established that there is an increase of $16.94 \%$ in total serum cholesterol at $(\mathrm{p}<0.0001)$. There is an increase of serum level of LDL and VLDL in rollups with $34.64 \%$ at $\mathrm{p}<0.001$ and $27.54 \%$ at $\mathrm{p}<0.01$. Our investigation was also established to be alike consequences. In smokers group the level of HDL is lower by $9.78 \%$ at $(\mathrm{p}<0.01)$. Smoking cigarette is the sole cause for developing chronic illness and also high mortality rate [1]. Now in the emerging world, tobacco habit is growing, chiefly amongst early persons [2]. Tobacco burning is intricate in the early progress of the initial phase of atherosclerotic CAD and CAD cardiovascular illness following an irregular danger issue.

There are several process results in lipid variation due to smoking, these are the amplified level of plasma-free fatty acid (FFA) concentration is high due to the triggering of sympathetic subreptic system which enhances the catecholamine discharge. This also raises the VLDL secretion, FFA and hepatic triglyceride. This change also alters the oestrogen level by dropping it drastically along with HDL. Lowering of lipoprotein action results due to hyperinsulinemia which in turn elevates the TGs, cholesterol and Ldl.

This investigation was performed to inspect the influence of lipid summaries on burning. Separately from non-smokers and smokers all 
contributors in our study were safe. Our study also found that LDL and TG level among the nonsmoker group was elevated and that of HDL was low in smoker group. Our conclusions are reliable with the answers of numerous investigators. Daily consumption of cigarettes and also prolong period of addiction elevates the level of lipoprotein in the blood. In disparity to these outcomes, Diricana et al. Established that serum TG, TC or LDL and HDL amid the two groups were not meaningfully fluctuating [14]. The results were approved $[3,11,15]$. The research of Nesje LA stated that there is a difference between two groups in terms of total cholesterol and triglycerides. This might be accredited to cultural populace changes in proceeding investigates [16]. The coronary artery disorder is triggered by dyslipidaemia, which is stated by one report. Our study revealed an analysis of dyslipidaemia among the smokers group. . Significant variables comprising physical activity, dietary habits and biology were not combined which might subsidize to cardiovascular alteration factors in young persons as the important inadequacies of this research.

Our investigation found that the serum VLDL, serum triglyceride (TG) were effectively higher in smoker group compared to non-smokers. As per the study of Sharma et al., Mouhamed et al., Fariduddin et al. [17-19] our investigation also found that one of the primary content of tobacco is nicotine. Cortisol and catecholamine secretion is prompted by nicotine. These two hormones are responsible for triggering adenylyl cyclase mainly in the adipose tissue resulting in an elevation of lipolysis and free fatty acid plasma release (FFFAA). The TG synthesis is elevated by the gathering of hepatocytes containing FFA's. VLDL elements are secreted as endogenous TG's. The levels of VLDL in serum and TG's are increased in a drastic level among the smokers [20]. The ester transfer protein (CETP) cholesterol probability is also increased along with VLDL and TG gathering with HDL upsurge. The exchange of CETP is usually noticed and takes place among TG and HDL and VLDL with the esters of cholesterol. CE-poor and TG-rich elements are fewer steady to deterioration and serum HDL points descent [21]. There is a correlation between the lower rate of HDL and higher rates of VLDL and TG. VLDL are imitative particles of LDL. Elevated level of LDL plasma is primarily due to higher amount of VLDL. With the decrease in HDL, level there is a lowering of reverse cholesterol transportation. This upsurges the accumulation of peripheral tissue lipid. The occurrence of atherosclerotic wounds in vascular endothelium is related with dyslipidaemia in extraordinary lower HDL, VLDL, TG systems [22]. It can also be assumed that this dyslipidaemia contributes to coronary artery disease [23].

It develops many diseases such as peripheral vascular diseases, lung diseases, and cerebrovascular diseases, which are autonomous and adaptable. Thus, it is important for the smokers for maintaining and checking both their health and their close surrounding once as passive smoking is also harmful and giving rise to complications [24]. To get rid of this hazard quitting smoking and maintaining healthy lifestyle is essential.

\section{Disclosure statement}

There was no conflict of interest in our study.

\section{Ethical committee approval}

Our study was initiated and completed following approval of our institutional ethical committee.

\section{References}

[1] Cuesta C, Sánchez-Muniz FJ, García-La Cuesta A, Garrido R, Castro A, et al. Effects of age and cigarette smoking on serum concentrations of lipids and apolipoproteins in a male military population. Atherosclerosis. 1989; 80(1):33.

[2] World Health Organization (WHO). Chronicle. 1983; 37:8690.

[3] Khurana M, Sharma D, Khandelwal PD. Lipid profile in smokers and tobacco chewers - a comparative study. J Assoc Physicians India. 2000; 48(9):895-897.

[4] Brischetto CS, Connor WE, Connor SL, Matarazzo JD. Plasma lipid and lipoprotein profile of cigarette smokers from randomly selected families. Enhancement of hyperlipidaemia and depression of HDL. Am J Cardiol. 1983; 52(7):675-680.

[5] Rosenson RS. Low level of HDL-cholesterol (Hypoalphalipoproteinemia). An approach to management. Arch Intern Med. 1993; 153(13):1528-1538.

[6] Sonaliya KN. The Economics of Tobacco In India. National J Med Res. 2012; 2(3):243-244.

[7] Gupta PC, Ray CS. Tobacco, education \& health. Indian J Med Res. 2007; 126(4):289-299.

[8] Mishra S, Joseph RA, Gupta PC, Pezzack B, Ram F, et al. Trends in bidi and cigarette smoking in India from 1998 to 2015, by age, gender and education. BMJ Global Health, 2016; 1(1):e000005.

[9] Adedeji OA, Etukudo MH. Lipid profile of cigarette smokers in Calabar municipality. Pak J Nutr. 2006; 5(30):237-238.

[10] Ayaori M, Hisa T, Suzukawa M, Yoshida H, Nishiwaki M, et al. Plasma level and redox status of ascorbic acid and level of lipid peroxidation product in active and passive smokers. Environ Health Perspect. 2000; 108(2):105-108. 
[11] Neki NS. Lipid profile in chronic smokers - A clinical study. Indian Acad Clin Med. 2005; 3(1):51-54.

[12] Jaleel A, Jaleel F, Majeed R, Alam E. Leptin and blood lipid level in smokers and ex smokers. World Appl Sci J. 2007; 2(4):248-352.

[13] Rao CS, Subash YE. The effect of chronic tobacco smoking and chewing on the lipid profile. J Clin Diagn Res. 2013; $7(1): 31-34$.

[14] US Department of Health \& Human Services (HHS). Preventing tobacco use among young people: A Report of the surgeon general. 1994; Vol.43.

[15] Suleyman H, Gumustekin K, Taysi S, Keles S, Oztasan N, et al. Beneficial effects of Hippo phae rhamnoides L. on nicotine induced oxidative stress in rat blood compared with vitamin E. Biol Pharm Bull. 2002; 25(9):1133-1136.

[16] Binder CJ, Shaw PX, Chang MK, Boullier A. The role of natural antibodies in atherogenesis. J Lipid Res. 2005; 46(7):13531363.

[17] Sharma P, Kumar P, Sharma R, Kishore K, Gupta G. Dyslipidemia among smokers. Asian J Pharm Clin Res. 2016; 9(4):137-138.

[18] Mouhamed DH, Ezzaher A, Neffati F, Gaha L, Douki W, et al. Association between cigarette smoking and dyslipidemia. Immuno-analyse \& Biologie Spécialisée 2013; 28(4):195200.

[19] Fariduddin JM, Masih SS. A comparative study on lipid profile and uric acid among smokers and non-smokers. Int J Clin Bioche Res. 2016; 3(4):469-471.

[20] Nelson RH. Hyperlipidemia as a risk factor for cardiovascular disease. Primary care. 2013; 40(1):195-211.

[21] Lee JS, Chang PY, Zhang Y, Kizer JR, Best LG, et al. Triglyceride and HDL-C dyslipidemia and risks of coronary heart disease and ischemic stroke by glycemic dysregulation status: The Strong Heart Study. Diabetes Care. 2017; 40(4):529-537.

[22] Peto J. That the effects of smoking should be measured in pack-years: misconceptions 4. British J Cancer. 2012; 107(3):406-407.

[23] Kawachi, Ichiro, Colditz GA. Workplace exposure to passive smoking and risk of cardiovascular disease: summary of epidemiologic studies. Environmental Health Perspectives. 1999; 107(Suppl 6):847-851.

[24] Wu J, Sin DD. Improved patient outcome with smoking cessation: when is it too late? Int J Chron Obstruct Pulmon Dis. 2011; 6:259-267. 